\title{
Psychiatric Emergencies During the Covid-19 Pandemic: A 6-Month Observational Study
}

\author{
Rosaria Di Lorenzo' \\ Nicoletta Frattini ${ }^{2}$ \\ Diego Dragone $\mathbb{1}^{3}$ \\ Riccardo Farina ${ }^{3}$ \\ Filippa Luisi ${ }^{3}$ \\ Silvia Ferrari $\left(\mathbb{D}^{3}\right.$ \\ Geminiano Bandiera (iD ${ }^{4}$ \\ Sergio Rovesti (iD) \\ Paola Ferri $\mathbb{1}^{5}$ \\ 'Psychiatric Intensive Treatment Facility, \\ Mental Health and Drug Abuse \\ Department of AUSL-Modena, Modena, \\ Italy; ${ }^{2}$ Department of Biomedical, \\ Metabolic and Neural Sciences, School of \\ Nursing, University of Modena and \\ Reggio Emilia, Modena, Italy; \\ ${ }^{3}$ Department of Biomedical, Metabolic \\ and Neural Sciences, School of \\ Psychiatry, University of Modena and \\ Reggio Emilia, Modena, Italy; ${ }^{4}$ Emergency \\ Room and Emergency Medicine Unit, \\ General Hospital of Baggiovara, AOU of \\ Modena, Modena, Italy; ${ }^{5}$ Department of \\ Biomedical, Metabolic and Neural \\ Sciences, University of Modena and \\ Reggio Emilia, Modena, Italy
}

Background: The new SARS-CoV-2 has caused an ongoing pandemic. Health prevention measures to contain the outbreak are profoundly affecting the physical and mental health as well as personal freedom of the population.

Aim: To evaluate psychiatric emergencies in a 6-month period during the COVID-19 pandemic in 2020 compared to those of the corresponding period of the previous year.

Methods: This monocentric observational study preliminarily collected variables of the urgent psychiatric consultations (UPCs) carried out in emergency room (ER) from 1-3-2020 to 31-8-2020 and the socio-demographic and clinical characteristics of patients who required UPCs in the 6-month period, comparing these data with those collected from 1-3-2019 to 31-8-2019. The data, collected in alpha-numeric code, were statistically analyzed through STATA 12-2011.

Results: This research reported a reduction of both UPCs and hospital psychiatric admissions. Concomitantly, we observed an increase of UPCs required by people already being treated by psychiatric and other health services, residents in psychiatric facilities and nonItalians. In 2020, differently from 2019, the most frequent reasons for urgent psychiatric consultations were aggressive behavior and adjustment disorders with anxiety and depressive mood.

Conclusion: This preliminary study suggests that, during the COVID-19 epidemic, urgent psychiatric consultations in ER were reduced, except for the most vulnerable people due to their clinical and/or social conditions.

Keywords: psychiatric emergencies, urgent psychiatric consultations, COVID-19 pandemic

\section{Introduction}

\section{Psychiatry of Catastrophes During COVID-19 Pandemic}

Catastrophes are defined as the events that cause such serious human and material losses as to exceed the coping resources of the community. ${ }^{1}$ These events trigger behavioural reactions and overwhelming emotions. The effects of catastrophes can lead to mental imbalance requiring specialized intervention and external support. ${ }^{2}$ Exposure to disasters represents an important risk factor in the development of mental health problems. ${ }^{3}$ In the field of "disaster psychiatry", the two most studied pathologies are post-traumatic stress disorder (PTSD) and major depression. A study conducted among the survivors of the Jiji earthquake, in Taiwan, found a considerable prevalence of these two diseases six months after the incident. In the following three years, a decrease in the percentage of PTSD and major depression concomitant to a significant increase in the rate of suicidal behaviour and alcohol and substance abuse were found. ${ }^{4}$ A study, implemented in the Fukushima district
Correspondence: Rosaria Di Lorenzo Psychiatrist, Psychiatric Intensive Treatment Facility, Mental Health and Drug Abuse Department of AUSLModena, Via Paul Harris, 175, Modena, 4II22, Italy

Email r.dilorenzo@ausl.mo.it 
after the nuclear power plant disaster reported a qualitative and quantitative variation in psychiatric service users in the district in the year of the disaster compared to the previous one: the number of individuals who required consultations and treatments increased, with a significant number of diagnoses of adjustment disorders and PTSD whereas, concomitantly, major depression was reduced. ${ }^{5}$ Following the earthquake in L'Aquila, which occurred in 2009, a study investigating the reasons for hospitalizations and for consultations in emergency room in the year of earthquake observed a substantial increase of cardiovascular, psychiatric, gynaecological, infectious and chronic diseases, while pneumological, gastroenterological, traumatic and "other" diseases decreased, plausibly related to the stress generated by the event. ${ }^{6}$ It is widely documented in the literature that exposure to trauma of catastrophic proportions causes psychological vulnerabilities in the population involved, for reasons attributable to both the social implications of the disaster and the negative effects of stress.

In the last months of 2019, several cases of unknown pneumonia occurred in Wuhan, Hubei province, China. Cases rapidly increased across the province and, in early 2020, also occurred in other states in China. In January 2020, the virus was identified in a patient's swab, classified as belonging to the coronavirus family and was named 2019nCoV by the World Health Organization (WHO). On 11 February 2020, the International Commission for the Taxonomy of Viruses renamed the virus as SARS-CoV-2, Severe Acute Respiratory Syndrome-Coronavirus-2. ${ }^{7-9}$ In Italy, the first coronavirus infections occurred in the region of Lombardy, initially only in a few small towns, then it spread rapidly to densely populated cities. From March 9 until May 3, 2020, the Italian government imposed a lockdown throughout the country, limiting travel across the country except for urgent and unpostponable work and health reasons, in an effort to contain the coronavirus spread. ${ }^{10,11}$

It is plausible to assume that the current COVID-19 pandemic, which is still uncontrolled and potentially dangerous, and the related "lockdown" measures are traumatizing for the world population. Since this is a situation that has never occurred before, there are still no reliable data or predictive models of the psychological reactions in the population following this event. However, a pattern in the incidence of psychiatric diseases in COVID-19 pandemic can be assumed analogous to other catastrophic events such as the SARS and H1N1 epidemics of past years. ${ }^{12,13}$ As WHO recently alerted, the COVID-19 pandemic represents a worldwide epidemic risk not only for infection but also for the development, exacerbation and relapse of many psychiatric and substance use disorders. ${ }^{14}$

In a recent article, an author indicates the diagnostic criteria for pandemic acute stress disorder induced by COVID-19, which belong to the category of acute stress disorder. The extent of the stressful experience includes many situations: becoming a victim of infection with an immediate threat to life, being a direct witness to such an event, staying in quarantine, confronting the death of close family and friends. The area of traumatic experiences also includes prolonged exposure to the consequences of commonly introduced hygienic-epidemic rules that limit freedom of action, access to goods, and existential possibilities. $^{15}$

The isolation, the state of uncertainty and the fear of infection have a strong impact on the emotional and psychological state of the population. Individuals with a certain or suspected infection may have experienced a strong sense of anguish about the evolution of the disease, while those who faced the period of forced confinement have experienced boredom and a sense of loneliness. ${ }^{12}$ A study conducted in 2015 in a sample of 1656 people in Korea highlighted anxiety symptoms (7.6\%) and feelings of anger (16.6\%) as effects on the population of the quarantine measures taken to prevent the spread of respiratory syndrome (MERS) in the Middle East; six months after the end of the quarantine, the same symptoms and feelings were still present in the population. ${ }^{16}$ Similarly, university students in Guangzhou, China, experienced panic (7.2\%), depression $(6.3 \%)$ or reported symptoms of emotional or mood disorders during the H1N1 epidemic. ${ }^{17}$ There are few articles about the 1918 flu pandemic, known as the Spanish Flu, and its effects on the mental health of the population due to the losses and the psychological trauma suffered by the people involved. ${ }^{18,19}$

A recent study identified four main types of vulnerabilities among patients with mental disorders during this pandemic: (1) medical comorbidities such as cardiovascular and pulmonary diseases, diabetes, obesity, etc., frequent conditions among patients with mental disorders, that are risk factors for severe COVID-19 infection; (2) age, since the elderly are the population most vulnerable to coronavirus; (3) cognitive and behavioural disturbances, which can hinder compliance with isolation and hygiene measures; and (4) psychosocial vulnerability-related 
stigmatization and/or socioeconomic difficulties. ${ }^{20}$ Furthermore, the mental health services can be more vulnerable than other health systems. Safety measures such as social isolation are poorly suited to psychiatric treatments in outpatient services institutions. In addition, a number of structural aspects make the psychiatric services particularly vulnerable: mental health community facilities are closed and medical teams are understaffed; maintaining the continuity of psychiatric care in this pandemic situation can be in opposition to safety isolation measures. There are also major problems when referring patients with acute mental disorders to intensive care units. ${ }^{20}$

Recent reviews of the literature about the current COVID-19 pandemic have highlighted that, since the beginning of the COVID-19 outbreak, the world population complained of psychological distress and symptoms of anxiety and depression, with a significant reduction of well-being. ${ }^{21,22}$ In Italy, just three weeks after the beginning of the virus containment measures, high rates of psychological sufferance such as stress and posttraumatic symptoms, both in the population and in health professionals, were recorded. $^{12}$ In January 2020, Wang et al administered a questionnaire to the Chinese population to collect data about the psychophysical states of anxiety, depression and stress two weeks from the beginning of the epidemic: $53.8 \%$ of respondents reported a moderate or severe impact of the outbreak on psychological status, $16.5 \%$ reported severe symptoms of depression while $28.8 \%$ reported significant symptoms of anxiety. ${ }^{23}$ Among patients already suffering from psychiatric disorders, symptoms of PTSD, feelings of anger, increased impulsivity and suicidal ideation were highlighted, probably due to not only to the emergency period, but, above all, to the containment measures and the isolation. Furthermore, the same patients obtained high scores on the scales "Impact of Events Scale - Revised (IES-R)" and "Depression, Anxiety and Stress Scale - 21 (DASS21)", which, respectively, measure the subjective stress due to traumatic events and the global level of anxiety, depression and stress. ${ }^{24} \mathrm{~A}$ review of current scientific evidence, conducted by Vindegaard, highlighted the increase of post-traumatic, anxious and depressive symptoms and a concomitant decrease of psychological wellbeing in the population. ${ }^{21}$ These data predict an increase in requests for psychiatric care in the post-emergency period and highlight how mental health issues related to the pandemic could evolve into long-lasting health problems. This prediction is also supported by the evidence emerging in previous studies, in which an increase in psychiatric diagnoses such as PTSD, substance and alcohol abuse and major depression, following the SARS and H1N1 epidemics, was found. Protective measures towards vulnerable people should be globally adopted and healthcare services should be strengthened through a more extensive use of modern means of telecommunications. ${ }^{21,25}$

The actual stressful period and social isolation may increase the risk of recurrence and new episodes of psychiatric disorders. In fact, people are forced now to live isolated because social distancing is the most effective strategy to limit the spread of the virus. However, social isolation, especially if protracted, may increase the risk of mental disorders such as anxiety, mood, addictive and thought disorders. In many countries, the pandemic emergency impacts on economic and social disruptions have been reported. ${ }^{26}$

\section{Psychiatric Emergencies in Emergency Room}

A psychiatric emergency (PE) is defined by the American Psychiatric Association as an acute disorder of thought, behaviour, mood or social relationships, requiring immediate intervention as reported by the patient, family members or social circle. ${ }^{27}$ Generally, PEs are represented by acute anxiety, agitation and/or aggressiveness in acute psychotic episode, manic episode, depressive disorders and suicidal behaviour. $^{28}$

In the Emergency Room (ER), the degree of emergency severity is assigned by nurse triage, which is used to "classify" the priority of patients' disorders giving them a colour code with a priority level based on the prognosis of clinical condition. The four-colour code, similar in most western countries, is standardized in order to define the order of patient access to treatments and care. ${ }^{29,30}$ For psychiatric emergencies, the intervention is aimed at comprehension of the crisis, temporary clinical stabilization and referral of the patient to the appropriate (inpatient or outpatient) setting. ${ }^{31}$ In case of differential diagnosis from somatic pathologies, clinical investigation should be deepened through diagnostic blood tests and/or specialist consultancies. $^{32}$ Some authors indicate seven main aspects to explore during the urgent psychiatric consultation (UPC): event triggering the crisis; suicidal or violent behaviour against others; comorbid medical conditions; mental and physical status; availability of personal resources; therapeutic relationship with physician/professionals; 
availability of health treatments. ${ }^{33}$ Psychological support in psychiatric emergency refers to the establishment of a therapeutic alliance between the health worker and the patient in order to offer an appropriate containment for psychological crisis, whereas drug treatment can be indicated for reducing anxiety and agitation when psychological containment is not sufficient. ${ }^{34}$ Nevertheless, the first outcome in psychiatric emergencies can be represented by the need to "de-escalate" a state of psychomotor agitation or a suicidal behaviour. De-escalation is a communication process aimed at reassuring the patient, restoring him/her to a calm state, without dangerous escalation of violence. At the same time, this process can foster a therapeutic alliance with the patient. ${ }^{34}$

The primary aim of this study was to evaluate the impact of COVID-19 pandemic on psychiatric emergencies. The secondary aim was to compare the sociodemographic and clinical characteristics of patients who required urgent psychiatric consultations (UPCs) in ER during a 6-month period of 2020 with those who required UPCs in the same 6-month period of 2019.

\section{Materials and Methods Study Design and Period of Data Collection}

This monocentric observational preliminary study collected variables of the urgent psychiatric consultations (UPCs) in ER carried out from 1-3-2020 to 31-8-20 and the socio-demographic and clinical characteristics of patients who required the UPCs in the 6-month period, comparing these data with those collected from 1-3-2019 to $31-8-2019$. The study period selected in 2020 consisted of three months in the restricted lockdown imposed by the Decree of the President of the Council of Ministers (DPCM) from 8 March 2020 to 3 May 2020 and the following three months, when the limitations were suspended. In particular, the social limitations set up by DPCM were represented by the absolute prohibition of any movement except for work or emergency; the closure of all institutes, cultural venues and the suspension of all sporting events, activities and competitions; the closure of all shops on festive and pre-festive days, except pharmacies, para-pharmacies, post-offices and food stores; the suspension of all civil and religious ceremonies and events; allowing the activities of bars and restaurants only from 6 am to $6 \mathrm{pm}$, with the obligation to respect social distancing. ${ }^{35}$ Subsequently, a new Prime Minister's
Decree on 11 March 2020 imposed new restrictions which were maintained until 3 May 2020: total closure of all shops except pharmacies, para-pharmacies, post offices and grocery stores, complete suspension of bar and restaurant activities with the exception of home deliveries and closure of hairdressers and beauty centers. ${ }^{36}$

During the 2020 study period, the province of Modena on $01 / 03 / 2020$ recorded 24 infected people, while on 31/ $08 / 2020$ the number of infected people had risen to $4334 .^{37}$

The local Mental Health Department is organized into four sectors: Adult, Child and Adolescent, Drug Abuse and Clinical Psychology. Adult Mental Health, through the Mental Health Centers (MHCs), provides diagnostic, therapy and rehabilitation treatments for adults in outpatient and inpatient services for a population of 703,203 individuals. It guarantees voluntary and compulsory hospitalizations to the public acute psychiatric ward (Psychiatric Diagnosis and Care Service) in the General Hospital OCSAE in Baggiovara (Modena) and urgent psychiatric consultations at Emergency Room (ER) of the two General Hospitals in Modena, OCSAE and Policlinico.

\section{Eligibility Criteria}

All individuals aged 18 or over who received UPC in ER of the two Modena General Hospitals during the two observation periods were enrolled.

\section{Selected Variables}

We collected the following information regarding UPC:

- Referral to UPC,

- Clinical motivations for UPC,

- Therapeutic prescriptions and/or administration in UPC,

- Supplementary diagnostic test and/or additional medical consultations,

- Short-stay observation in ER: an access modality which permits patients to remain in ER for 24 hours in order to undergo further medical examinations or to wait for the availability of a bed in a psychiatric unit,

- UPC outcomes.

We collected the following variables related to the individuals who required UPC:

- Age,

- Gender,

- Nationality,

- Marital status,

- Living environment, 
- Occupational status;

- Previous treatment and care in outpatient services;

- Psychiatric diagnosis according to the classification system (ICD-9-CM) ${ }^{38}$ in accordance with local guideline indications;

- Double diagnosis of substance/alcohol use;

- Medical comorbidity;

- UPC number in the observation periods.

Data were collected from two different sources: the ER database for clinical data of UPCs integrated with data from the database of psychiatric outpatient services for demographic and clinical data of patients already in care at MHC.

\section{Statistical Analysis}

We used descriptive statistical analysis of variables: mean and standard deviation, $t$-test for analysis of continuous variables; percentages, Pearson chi2 tests or Fisher's exact test and posthoc testing using Bonferroni correction for categorical variables; multiple logistic regression, stepwise backward model, between the dependent variable "UPC" (UPC in 2020=1, UPC in 2019=0) and all demographic and clinical patient variables and all UPC but one (UPC outcome) selected variables, as independent ones. The level of statistical significance was set at $\mathrm{p}<0.05$. Data were analyzed through STATA12-2011.

\section{Ethical Considerations}

This research was conducted following the principles of the Declaration of Helsinki and according to good clinical practice behaviour. This study was approved by the Ethics Committee of the Vasta Emilia Nord Area (protocol n. 1265/2020/OSS/AOUMO; protocol n. 0035176/20 and protocol n. 0035169/20 of 03/12/2020).

Only the study manager and collaborators have had access to the data to respect confidentiality. Data were processed according to privacy regulations. The data were stored anonymously and identified on the basis of the assigned alphanumeric code.

\section{Results}

\section{Urgent Psychiatric Consultations (UPCs) Due to Psychiatric Emergency (PE) in ER During the 6-Month Observation Periods of 2019 and 2020}

We recorded 602 urgent psychiatric consultations (UPCs) due to PE carried out in the six months of observation in 2019 and 476 in the six months of observation in 2020, with a statistically significant difference in the number of consultations performed in each month between the two years. Nineteen UPCs, 12 in 2019 and 7 in 2020, were not completed due to the patients' refusal to participate in the UPC.

As shown in Figure 1, in March 2020 only 44 UPCs $(9.2 \%)$ were performed in comparison with those carried out in $2019(\mathrm{n}=98,16.2 \%)$ and in the other months also a reduced number of UPCs were carried out in 2020 compared to 2019. For each UPC, different characteristics were found. The patient's referral to UPC was statistically

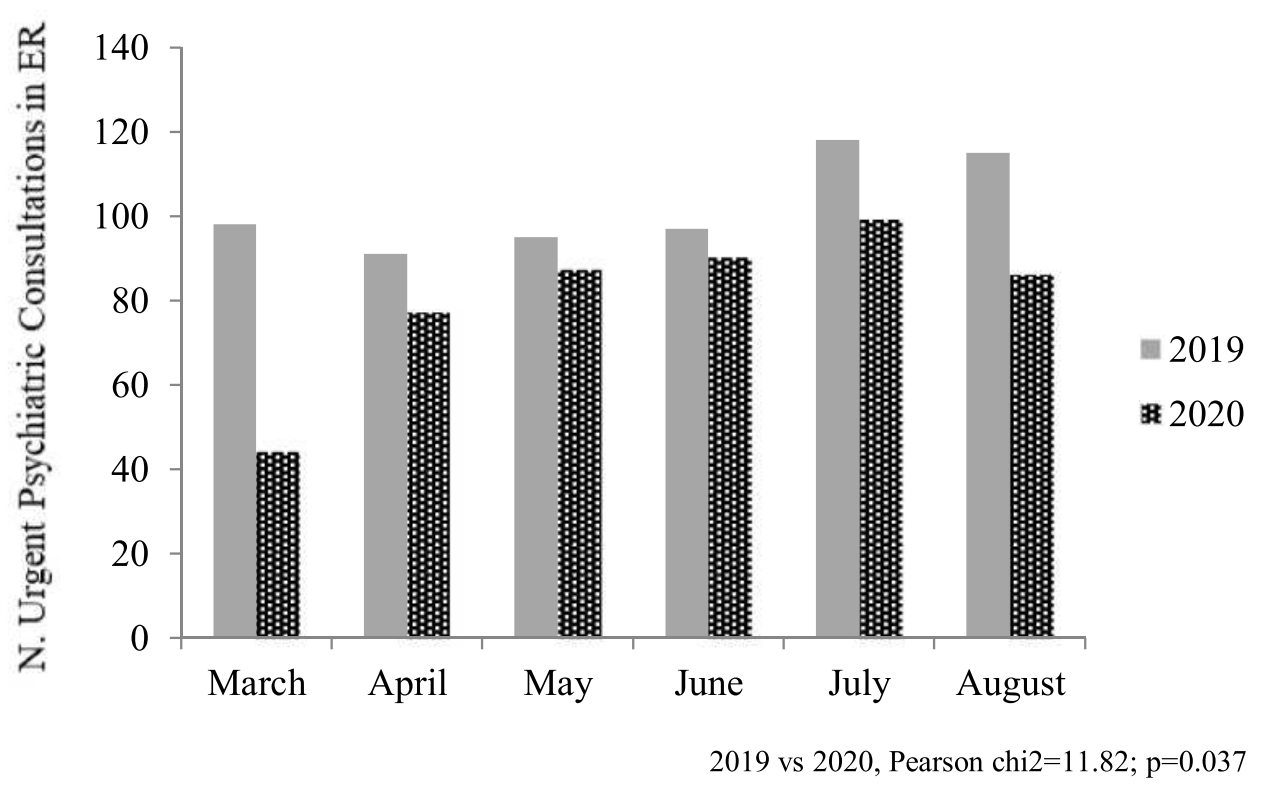

Figure I Urgent psychiatric consultations (UPC) in ER during the 6-month periods in 2019 and 2020. 
significantly different in the observation periods of the two years: in 2020, we observed a significant increase in patient's referral to UPC from psychiatric facilities $(6 \%)$ compared to the previous year (2\%) (Table 1). The clinical motivations for UPC in ER were grouped in accordance with the prevalence observed in our sample and are represented by ten groups of conditions: suicidal behaviour, acute psychosis, depressive disorders, anxiety disorders, aggressiveness, maladjustment disorders with anxiety and depressive mood, drug intoxication, psychiatric symptoms in medical conditions, manic episode and other. As shown in Table 1, motivations for UPCs were statistically significantly different between the two observation periods of 2019 and 2020. In particular, the greatest differences were found in suicidal behaviour, which included suicidal ideation, suicide attempts and para-suicidal behaviors ${ }^{39}$ (17.3\% in 2019 and $14.1 \%$ in 2020), aggressiveness (3.8\% in 2019 and $10.7 \%$ in 2020), maladjustment disorders ( $2 \%$ in 2019 and $7.8 \%$ in 2020 ) and manic episode ( $8 \%$ in 2019 and $2.9 \%$ in 2020 ).

In the Emergency Room, various clinical activities relating to the consultations were implemented (Table 2). Statistically significant differences were highlighted in the two observation periods as regards the therapeutic measures implemented, with more frequent pharmacological administration in 2019 (32.6\%) in comparison with 2020 (23.7\%), whereas drug prescription was prevalent in 2020 (32.3\%) compared to 2019 (23.1\%). On the other hand, there were no statistically significant differences regarding the short-stay observation in ER or the request for supplementary diagnostic test and/or medical consultations between the two years (Table 2). The outcome of psychiatric consultations was statistically significantly different between the two years, as shown in Table 2: in 2020, both the voluntary and involuntary hospitalizations were reduced whereas discharges at home and referral to MHC were increased in comparison with the previous year.

\section{The Characteristics of Individuals Who Required UPCs in ER in the 6-Month Observation Periods of 2019 and 2020}

We reported a different number of individuals who required urgent psychiatric consultations in ER during the two observation periods: 479 patients in 2019 and 395 patients in 2020, of which 62 in 2019 and 66 in 2020 required two or more UPCs. As shown in Table 3, the socio-demographic characteristics of individuals who

Table I UPCs for Psychiatric Emergency in ER During the 6-Month Observation Periods in 2019 and 2020

\begin{tabular}{|c|c|c|c|c|}
\hline Variables & $\begin{array}{l}\text { UPCs from } \\
\text { I March } \\
\text { to } 31 \text { August } \\
2019 \\
(n=602)\end{array}$ & $\begin{array}{l}\text { UPCs from } \\
\text { I March } \\
\text { to } 3 \text { I August } \\
2020 \\
(n=476)\end{array}$ & Statistical Test & Probability \\
\hline \multicolumn{5}{|c|}{ Clinical motivations for PEs, $\mathrm{n}(\%)$} \\
\hline $\begin{array}{l}\text { Suicidal behaviour } \\
\text { Acute psychosis } \\
\text { Depressive disorders } \\
\text { Anxiety disorders } \\
\text { Aggressiveness } \\
\text { Maladjustment disorder with anxiety and/or depressed } \\
\text { mood } \\
\text { Drug intoxication } \\
\text { Psychiatric symptoms in medical conditions } \\
\text { Manic episode } \\
\text { Others (anorexia, and other eating disturbances) }\end{array}$ & $\begin{array}{l}103(17.3 \%) \\
64(10.6 \%) \\
82(13.6 \%) \\
140(23.3 \%) \\
23(3.8 \%) \\
12(2 \%) \\
59(9.8 \%) \\
11(1.8 \%) \\
48(8 \%)^{\S} \\
60(10 \%)^{\S}\end{array}$ & $\begin{array}{l}67(14.1 \%) \\
46(9.7 \%) \\
61(12.8 \%) \\
106(22.3 \%) \\
51(10.7 \%)^{\S} \\
37(7.8 \%)^{\S} \\
50(10.5 \%) \\
22(4.6 \%)^{\S} \\
14(2.9 \%) \\
22(4.6 \%)\end{array}$ & $\begin{array}{c}\text { Pearson } \\
\text { chi2 }=68.58 \\
\text { §Bonferroni } \\
\text { correction }\end{array}$ & $\begin{array}{l}P=0.000 \\
p<0.05\end{array}$ \\
\hline \multicolumn{5}{|c|}{ Referral to UPCs, n (\%) } \\
\hline $\begin{array}{l}\text { Spontaneous/General practitioner } \\
\text { MHC } \\
\text { Psychiatric facilities } \\
\text { Other medical specialists }\end{array}$ & $\begin{array}{l}567(94.2 \%) \\
1(0.2 \%) \\
12(2 \%) \\
22(3.6 \%)\end{array}$ & $\begin{array}{l}430(90.3 \%) \\
3(0.6 \%) \\
29(6 \%)^{\S} \\
14(2.9 \%)\end{array}$ & $\begin{array}{l}\text { Fisher's exact } \\
\text { §Bonferroni } \\
\text { correction }\end{array}$ & $\begin{array}{c}P=0.002 \\
p<0.05\end{array}$ \\
\hline
\end{tabular}

Note: §Statistically significant percentage at post-hoc testing using Bonferroni correction. 
Table 2 Clinical Activities Performed in UPCs During the 6-Month Observation Periods in 2019 and 2020

\begin{tabular}{|c|c|c|c|c|}
\hline Variables & $\begin{array}{l}\text { UPCs } \\
\text { from I March } \\
\text { to } 3 \text { I August } \\
2019 \\
(n=602)\end{array}$ & $\begin{array}{l}\text { UPCs } \\
\text { from I March } \\
\text { to } 31 \text { August } \\
2020 \\
(n=476)\end{array}$ & Statistical Test & Probability \\
\hline \multicolumn{5}{|c|}{ Therapy prescription and/or administration, $\mathrm{n}$ (\%) } \\
\hline $\begin{array}{l}\text { No drug prescription and/or administration } \\
\text { Drug prescription } \\
\text { Drug administration } \\
\text { Drug prescription } \\
\text { and administration }\end{array}$ & $\begin{array}{l}267(44.4 \%) \\
139(23.1 \%) \\
196(32.6 \%) \S \\
33(5.5 \%)\end{array}$ & $\begin{array}{c}209(43.9 \%) \\
154(32.4 \%) \S \\
113(23.7 \%) \\
24(5 \%)\end{array}$ & $\begin{array}{l}\text { Pearson } \\
\text { chi2 }=15.62 \\
\S \text { Bonferroni } \\
\text { correction }\end{array}$ & $\begin{array}{l}P=0.000 \\
P<0.05\end{array}$ \\
\hline \multicolumn{5}{|c|}{ Short-Stay observation in ER, $\mathrm{n}(\%)$} \\
\hline $\begin{array}{l}\text { No short-stay observation } \\
\text { Short-stay observation of I or } 2 \text { days }\end{array}$ & $\begin{array}{c}536(89 \%) \\
66(11 \%)\end{array}$ & $\begin{array}{c}433(91 \%) \\
43(9 \%)\end{array}$ & Pearson chi2 $=1.0892$ & $p=0.297$ \\
\hline \multicolumn{5}{|c|}{ Supplementary diagnostic test and/or additional medical consultations, n (\%) } \\
\hline $\begin{array}{l}\text { Necessary } \\
\text { Not necessary }\end{array}$ & $\begin{array}{l}509(84.5 \%) \\
93(15.4 \%)\end{array}$ & $\begin{array}{l}394(82.8 \%) \\
82(17.2 \%)\end{array}$ & Pearson chi2 $=0.6182$ & $\mathrm{P}=0.432$ \\
\hline \multicolumn{5}{|c|}{ Outcomes of UPC, n (\%) } \\
\hline $\begin{array}{l}\text { Voluntary psychiatric hospitalization } \\
\text { Involuntary psychiatric hospitalization } \\
\text { Discharge at home and referral to general practitioner } \\
\text { Discharge at home and referral to MHC } \\
\text { Discharge at home and referral to Drug Abuse Center } \\
\text { Discharge at home and referral to GP } \\
\text { Discharge at home and referral to other medical specialists } \\
\text { Discharge at home and referral to more than one outpatient } \\
\text { service }\end{array}$ & $\begin{array}{l}15 \mid(25.1 \%) \\
12(2 \%) \\
78(13 \%) \\
25 \mid(41.7 \%) \\
33(5.5 \%) \\
33(5.5 \%) \\
21(3.5 \%) \\
23(3.8 \%) \S\end{array}$ & $\begin{array}{c}99(20.8 \%) \\
6(1.3 \%) \\
45(9.5 \%) \\
237(49.8 \%) \S \\
22(4.6 \%) \\
32(6.7 \%) \\
30(6.3 \%) \S \\
5(1 \%)\end{array}$ & $\begin{array}{c}\text { Pearson chi } 2=23.03 \\
\S B o n f e r r o n i \\
\text { correction }\end{array}$ & $\begin{array}{l}P=0.002 \\
P<0.05\end{array}$ \\
\hline
\end{tabular}

Note: §Statistically significant percentage at post-hoc testing using Bonferroni correction.

required UPC at ER in the observation periods of 2019 and 2020 were not statistically significantly different between the two years. In 2020, Italians who required UPC decreased whereas European non-Italians increased in comparison to the previous year. For $3(0.3 \%)$ patients, in the two observation periods, it was not possible to detect the nationality. We observed that in 2020 the prevalence of patients was males in contrast to 2019 when females were prevalent and older than in 2019 but without any statistically significant difference. In both years, the majority of patients were single and lived in acquired or parental family. For 121 (25.7\%) patients in 2019 and 116 (29.4\%) patients in 2020, it was not possible to register the marital status. The housing environment was not statistically significantly different in the two years, although we registered an increase in patients living in psychiatric facilities in 2020 (4.8\%) in comparison with 2019 $(1.5 \%)$. Regarding work status, we reported a statistically significant difference in the comparison between the two years: in 2020, more employed (27.3\%), retired (10.1\%), pensioner for disability patients $(4.6 \%)$ were found whereas students $(3.8 \%)$ were reduced in comparison with 2019.

As regards the psychiatric diagnoses, coded by ICD9-CM, of individuals who required UPC, we did not observe any statistically significant difference in the two observation periods (Table 4). More than one third of individuals who received UPC in 2019 and 2020 had not previously been diagnosed with any psychiatric disorders. Among the patients with previous psychiatric diagnosis, in 2020, we observed an increase of individuals with bipolar disorders (6.1\%), personality disorders $(13.7 \%)$ and adjustment disorders $(9.4 \%)$ and a reduction of individuals with depressive disorders $(9.1 \%)$ and alcohol/substance abuse and dependence (1.8\%), in comparison with 2019, without any statistically significant 
Table 3 Demographic Characteristics of Individuals Who Required UPC During the 6-Month Observation Periods in 2019 and 2020

\begin{tabular}{|c|c|c|c|c|}
\hline Variables & $\begin{array}{l}\text { Individuals Who Required UPC from } \\
\text { I March to } 3 \text { I August } 2019 \\
(n=470)\end{array}$ & $\begin{array}{l}\text { Individuals Who Required UPC from } \\
\text { I March to 3I August } 2020(n=395)\end{array}$ & $\begin{array}{l}\text { Statistical } \\
\text { Test }\end{array}$ & Probability \\
\hline \multicolumn{5}{|c|}{ Gender, n (\%) } \\
\hline Male & 222 (47.2\%) & 205 (51.9\%) & Pearson & $p=0.247$ \\
\hline Female & $248(52.8 \%)$ & $190(48.1 \%)$ & chi $2=2.80$ & \\
\hline \multicolumn{5}{|c|}{ Age, $m \pm D S$} \\
\hline Year & $44.1 \pm 17.33$ & $46.0 \pm 19.24$ & $\begin{array}{c}t=-1.4897 \\
t \text {-test }\end{array}$ & $\mathrm{p}=0.1367$ \\
\hline \multicolumn{5}{|c|}{ Nationality, n (\%) } \\
\hline $\begin{array}{l}\text { Italian } \\
\text { European } \\
\text { non-Italian } \\
\text { Not } \\
\text { European } \\
\text { Unknown }\end{array}$ & $\begin{array}{c}384(81.7 \%) \\
24(5.1 \%) \\
60(12.8 \%) \\
2(0.4 \%)\end{array}$ & $\begin{array}{c}307(77.7 \%) \\
32(8.1 \%) \\
55(13.9 \%) \\
I(0.3 \%)\end{array}$ & $\begin{array}{c}\text { Pearson } \\
\text { chi2 } 2=3.80\end{array}$ & $\mathrm{P}=0.284$ \\
\hline \multicolumn{5}{|c|}{ Marital status, n (\%) } \\
\hline $\begin{array}{l}\text { Single } \\
\text { Married } \\
\text { Divorced } \\
\text { Widowed } \\
\text { Unknown }\end{array}$ & $\begin{array}{l}17 \mid(36.4 \%) \\
125(26.6 \%) \\
40(8.5 \%) \\
13(2.8 \%) \\
12 \mid(25.7 \%)\end{array}$ & $\begin{array}{c}139(35.2 \%) \\
102(25.8 \%) \\
27(6.8 \%) \\
\text { II (2.8\%) } \\
\text { II }(29.4 \%)\end{array}$ & $\begin{array}{c}\text { Pearson } \\
\text { chi2 }=1.94\end{array}$ & $\mathrm{P}=0.747$ \\
\hline \multicolumn{5}{|c|}{ Living environment, n (\%) } \\
\hline $\begin{array}{l}\text { Parental } \\
\text { house } \\
\text { Married } \\
\text { family } \\
\text { Alone } \\
\text { Protected } \\
\text { facility } \\
\text { Homeless } \\
\text { Other }\end{array}$ & $\begin{array}{l}109(23.2 \%) \\
133(28.3 \%) \\
48(10 \%) \\
7(1.5 \%) \\
11(2.3 \%) \\
157(33.4 \%)\end{array}$ & $\begin{array}{c}86(21.8 \%) \\
111(28.1 \%) \\
42(10.6 \%) \\
19(4.8 \%) \\
7(1.8 \%) \\
129(33.7 \%)\end{array}$ & $\begin{array}{c}\text { Pearson } \\
\text { chi2 }=9.55\end{array}$ & $p=0.145$ \\
\hline \multicolumn{5}{|c|}{ Occupational status, n (\%) } \\
\hline $\begin{array}{l}\text { Unemployed } \\
\text { Employed } \\
\text { Student } \\
\text { Retired } \\
\text { Disability } \\
\text { pension } \\
\text { Unknown }\end{array}$ & $\begin{array}{c}109(223.2 \%) \\
115(24.5 \%) \\
28(6 \%) \\
37(7.9 \%) \\
10(2.1 \%) \\
171(36.4 \%)\end{array}$ & $\begin{array}{c}90(22.8 \%) \\
108(27.3 \%) \\
15(3.8 \%) \\
40(10.1 \%) \\
18(4.6 \%) \\
124(31.4 \%)\end{array}$ & $\begin{array}{c}\text { Pearson } \\
\text { chi2=9.42 }\end{array}$ & $\mathrm{P}=0.093$ \\
\hline
\end{tabular}

difference. We observed a statistically significant difference between the two years in the number of individuals previously in treatment and care at $\mathrm{MHC}$ and not previously treated in $\mathrm{MHC}$ or other outpatient services, as shown in Table 5. In particular, in 2020, more patients previously treated in $\mathrm{MHC}$ and a reduced number of individuals not previously treated in MHC or other outpatient services required UPC in comparison with 2019. 
Table 4 Psychiatric Diagnoses (ICD-9-CM) of Individuals Who Presented PE During the 6-Month Observation Periods in 2019 and 2020

\begin{tabular}{|c|c|c|c|c|}
\hline Variables & $\begin{array}{l}\text { Individuals with PEs from } \\
\text { I March } \\
\text { to } 31 \text { August } \\
2019 \\
(n=470)\end{array}$ & $\begin{array}{c}\text { Individuals with } \\
\text { PEs } \\
\text { from I March } \\
\text { to } 3 \text { I August } \\
2020 \\
(n=395)\end{array}$ & $\begin{array}{c}\text { Statistical Test } \\
\text { Probability }\end{array}$ & Probability \\
\hline $\begin{array}{l}\text { No previous psychiatric diagnosis } \\
\text { Organic psychotic conditions } \\
\text { Schizophrenic disorders } \\
\text { Bipolar disorders } \\
\text { Depressive disorders } \\
\text { Anxiety disorders } \\
\text { Personality disorders } \\
\text { Alcohol/substance abuse and } \\
\text { dependence } \\
\text { Adjustment disorders } \\
\text { Mental retardation } \\
\text { Other }\end{array}$ & $\begin{array}{l}175(37.2 \%) \\
2 I(4.5 \%) \\
56(11.9 \%) \\
22(4.7 \%) \\
58(12.3 \%) \\
27(5.7 \%) \\
48(10.2 \%) \\
11(2.3 \%) \\
4 I(8.7 \%) \\
7(1.5 \%) \\
4(0.85 \%)\end{array}$ & $\begin{array}{c}144(36.5 \%) \\
16(4.1 \%) \\
46(11.6 \%) \\
24(6.1 \%) \\
36(9.1 \%) \\
20(5.1 \%) \\
54(13.7 \%) \\
7(1.8 \%) \\
37(9.4 \%) \\
7(1.8 \%) \\
4(1 \%)\end{array}$ & Pearson chi2 $=7.0147$ & $p=0.724$ \\
\hline
\end{tabular}

Regarding the dual diagnosis, we observed a statistically significant difference between the two years: in 2020, a reduced number of individuals with alcohol and substance abuse and more individuals without any abuse required UPC in comparison with 2019 (Table 5). For $16(1.8 \%)$ patients in total it was not possible to ascertain whether or not there was any pathological alcohol/substance use. The medical comorbidity was also statistically significantly different between the two observed periods (Table 5). In 2020, we reported a lower percentage of patients who presented medical comorbidity (79.5\%), compared to $2019(85.1 \%)$. For only $11(1.3 \%)$ patients it was not possible to detect the presence or absence of medical comorbidities.

\section{The Multiple Logistic Regression Between UPC and Selected Variables}

The selected variables statistically significantly related to UPC (dependent variable) carried out in the two years (UPC in $2020=1 ; 2019=0$ ) at multiple logistic regression, stepwise backward model, are represented by the following predictive variables of UPC in 2020 with OR >1 (Table 6):

- living in psychiatric facilities among housing environment,

- maladjustment disorders among clinical motivations for UPC,
- previous treatment and care at MHC,

- absent medical comorbidity.

In contrast, being student among work status, manic state among clinical motivations for UPC, substance and alcohol use in comorbidity among dual diagnosis, other clinical motivations for UPC, and previous psychiatric diagnosis were the protective variables for UPC in 2020 with $\mathrm{OR}<1$ (Table 6).

\section{Discussion}

This preliminary study was focused on the evaluation of urgent consultations in ER for psychiatric emergencies during the coronavirus epidemic spread and the related measures of social isolation in Italy. In particular, this study evaluated the period between 1 March and 31 August 2020, which included the three lockdown months and the three following ones, compared with the same period of 2019 .

The period of health emergency caused by COVID19 led to the reshaping of the mental health service activities, in both out- and inpatient settings, with the fundamental objective of guaranteeing the highest level of care in restrictive safety measures due to the pandemic. ${ }^{40}$ The planned outpatient activities of $\mathrm{MHC}$ were reassessed through telephone contacts and video calls in order to maintain the support of patients and their families even in social isolation. The availability 
Table 5 Clinical Characteristics of Individuals Who Presented PE During the 6-Month Observation Periods in 2019 and 2020

\begin{tabular}{|c|c|c|c|c|}
\hline Variables & $\begin{array}{c}\text { Individuals with PEs } \\
\text { from I March } \\
\text { to } 31 \text { August } \\
2019 \\
(n=470)\end{array}$ & $\begin{array}{c}\text { Individuals with PEs } \\
\text { from I March } \\
\text { to } 31 \text { August } \\
2020 \\
(n=395)\end{array}$ & Statistical Test & Probability \\
\hline \multicolumn{4}{|c|}{ Previous treatment and care, $\mathrm{n}(\%)$} & \\
\hline $\begin{array}{l}\text { MHC } \\
\text { Drug Abuse Center } \\
\text { Other specialists } \\
\text { Other or more than one outpatient services } \\
\text { Not previously treated in MHC or other } \\
\text { outpatient services }\end{array}$ & $\begin{array}{c}166(35.3 \%) \\
12(2.6 \%) \\
24(5.1 \%) \S \\
28(6 \%) \S \\
240(51.1 \%) \S\end{array}$ & $\begin{array}{c}240(60.8 \%) \S \\
0(0 \%) \\
1(0.3 \%) \\
2(0.5 \%) \\
152(38.5 \%)\end{array}$ & $\begin{array}{l}\text { Fisher's exact } \\
\text { §Bonferroni } \\
\text { correction }\end{array}$ & $\begin{array}{l}P=0.000 \\
P<0.05\end{array}$ \\
\hline \multicolumn{4}{|c|}{ Dual diagnosis, n (\%) } & \\
\hline $\begin{array}{l}\text { Not present } \\
\text { Non-specified substances } \\
\text { Alcohol } \\
\text { Alcohol + substance } \\
\text { Cannabis } \\
\text { Cocaine } \\
\text { Opioids } \\
\text { Unknown }\end{array}$ & $\begin{array}{c}330(70.2 \%) \\
37(7.9 \%) \S \\
45(9.6 \%) \\
28(6 \%) \S \\
10(2.1 \%) \\
5(1.1 \%) \\
2(0.4 \%) \\
13(2.8 \%)\end{array}$ & $\begin{array}{c}311(78.7 \%) \S \\
13(3.3 \%) \\
42(10.6 \%) \\
4(1 \%) \\
10(2.5 \%) \\
10(2.5 \%) \\
2(0.5 \%) \\
3(0.8 \%)\end{array}$ & $\begin{array}{l}\text { Fisher's exact } \\
\S \text { Bonferroni } \\
\text { correction }\end{array}$ & $\begin{array}{l}P=0.000 \\
P<0.05\end{array}$ \\
\hline \multicolumn{4}{|c|}{ Medical comorbidity, n (\%) } & \\
\hline $\begin{array}{l}\text { Present } \\
\text { Not present } \\
\text { Unknown }\end{array}$ & $\begin{array}{c}62(13.2 \%) \S \\
400(85.1 \%) \\
8(1.7 \%)\end{array}$ & $\begin{array}{c}78(19.7 \%) \\
314(79.5 \%) \S \\
3(0.8 \%)\end{array}$ & $\begin{array}{l}\text { Fisher's exact } \\
\S \text { Bonferroni } \\
\text { correction }\end{array}$ & $\begin{array}{l}P=0.01 \\
P<0.05\end{array}$ \\
\hline \multicolumn{4}{|c|}{ UPC per individual, n (\%) } & \\
\hline $\begin{array}{l}\text { One UPC } \\
\text { More than one UPC }\end{array}$ & $\begin{array}{l}408(86.8 \%) \\
62(13.2 \%)\end{array}$ & $\begin{array}{c}329(83.3 \%) \\
66(16.7 \%)\end{array}$ & $\begin{array}{c}\text { Pearson } \\
\text { chi2 }=2.1061\end{array}$ & $\mathrm{p}=0.147$ \\
\hline
\end{tabular}

Note: §Statistically significant percentage at post-hoc testing using Bonferroni correction.

of unscheduled urgent consultations for psychiatric emergencies, during regular service opening hours, was assured, but not the routine activities at Day-Hospital and/or residential facilities, where the daily presence of patients was drastically reduced in order to limit crowding, in accordance with safety measures. All group activities involving the simultaneous presence of several professionals were suspended during pandemic and reorganized. Hospital admissions in acute psychiatric wards were limited as much as possible in order to avoid COVID-19 outbreaks. Therefore, the non-urgent clinical activities and many psychotherapy interventions in outpatient service were deferred to the end of the epidemic. $^{40}$

In the emergency pandemic of 2020, we observed a relevant reduction in the number of UPCs, as observed by other authors in Italy and all over the world, in line with the general reduction of all consultations in ER obviously excluding those related to SARS-CoV-2. ${ }^{41-45}$ Differently, we observed an increase in the total and daily number of the UPCs performed at the outpatient Mental Health Center of Modena during the coronavirus outbreak period, from 1 March to 31 August 2020, in comparison with the same period in 2019, often required by the most clinically and socially vulnerable patients in care at local outpatient services. ${ }^{46}$ The emergency conditions have led the health system to reorganize the Emergency Departments, imposing filter to accesses which, in turn, has reduced all accesses to the emergency rooms other than for COVID-19 infection due to the risk of contagion. This reduction, which appeared in particular in the first month of the pandemic explosion in Italy, 
Table 6 Multiple Logistic Regression Between UPC (UPC in $2020=1$, UPC in 2019=0) and Statistically Significantly Related Variables

\begin{tabular}{|l|l|l|l|l|}
\hline Variables & $\begin{array}{l}\text { Odds } \\
\text { Ratio }\end{array}$ & $\begin{array}{l}\text { Std. } \\
\text { Err. }\end{array}$ & Probability & $\begin{array}{l}95 \% \\
\text { Conf. } \\
\text { Interval }\end{array}$ \\
\hline $\begin{array}{l}\text { Housing environment: } \\
\text { Psychiatric facilities }\end{array}$ & 7.60 & 5.35 & 0.004 & $\begin{array}{l}1.91 ; \\
30.21\end{array}$ \\
\hline $\begin{array}{l}\text { Clinical motivations } \\
\text { for UPC: }\end{array}$ & 4.38 & 1.92 & 0.001 & $\begin{array}{l}1.86 ; \\
\text { Maladjustment } \\
\text { disorders with anxiety } \\
\text { and depressive moods }\end{array}$ \\
\hline $\begin{array}{l}\text { Previous treatment } \\
\text { and care: } \\
\text { MHC }\end{array}$ & 5.99 & 1.79 & 0.000 & $\begin{array}{l}0.34 \\
10.77\end{array}$ \\
\hline $\begin{array}{l}\text { Medical comorbidity: } \\
\text { Absent }\end{array}$ & 1.69 & 0.43 & 0.037 & $\begin{array}{l}1.03 ; \\
2.77\end{array}$ \\
\hline $\begin{array}{l}\text { Work status: } \\
\text { Student }\end{array}$ & 0.43 & 0.13 & 0.007 & $\begin{array}{l}0.23 ; \\
0.79\end{array}$ \\
\hline $\begin{array}{l}\text { Clinical motivations } \\
\text { for UPC: } \\
\text { Manic state }\end{array}$ & 0.38 & 0.15 & 0.012 & $\begin{array}{l}0.18 ; \\
0.81\end{array}$ \\
\hline $\begin{array}{l}\text { Dual diagnosis: } \\
\text { Substance+alcohol in } \\
\text { comorbidity }\end{array}$ & 0.13 & 0.074 & 0.000 & $\begin{array}{l}0.04 ; \\
0.39\end{array}$ \\
\hline $\begin{array}{l}\text { Clinical motivations } \\
\text { for UPC: } \\
\text { Others }\end{array}$ & 0.52 & 0.17 & 0.047 & $\begin{array}{l}0.28 ; \\
0.99\end{array}$ \\
\hline $\begin{array}{l}\text { Previous psychiatric } \\
\text { Present }\end{array}$ & 0.31 & 0.10 & 0.001 & $\begin{array}{l}0.16 ; \\
0.61\end{array}$ \\
\hline
\end{tabular}

March 2020, was therefore an expected result that has been confirmed by another Italian study. ${ }^{44,47}$ In particular, we reported the reduction of spontaneous referral to UPC may be due to both the restricted lockdown measures and the fear of infection contagious in ER. ${ }^{42}$ On the other hand, in 2020, we reported the increase of UPCs required by the most vulnerable people due to their clinical and/or social conditions, as suggested by the higher number of people living in psychiatric facilities and already treated in MHC, in line with the results of our previous study implemented in the outpatient Mental Health Center of Modena in the same period. ${ }^{46}$ Although apparently in contrast with the general trend of UPCs, these results highlight the greater fragility of patients suffering from psychiatric pathology during pandemic, for whom ER remained the only place where they could ask for help, as suggested by other studies. ${ }^{12,23,44}$ Patients staying at the facilities may have suffered from problems related to "forced coexistence", 24 hours a day, with other residents due to the inevitably severe lockdown, applied in Italy especially from March to May 2020 to prevent the spread of the virus. ${ }^{48}$ The increase of UPCs required by patients already treated in MHC can be explained by the necessary reduction of clinical activities provided by MHC due to safety measures. Some of these, in fact, could only be carried out through telephone contact, such as consultancy with one's nurse of reference, whereas other activities were totally suspended until the end of the state of emergency, such as group activities and semi-residential activities. ${ }^{34,46}$ In accordance with some recent studies, despite remote interviews and telephone calls, the patient population taken into care by the outpatient services has received less psychological support and psychiatric treatments. ${ }^{49}$ Concerns about tele-psychiatry have been expressed by both users and especially by professionals, reporting the loss of personal contact, which can limit the building of therapeutic relationship, although it can represent the only instrument now available to maintain the continuity of care in a regular setting. ${ }^{50,51}$ Patients with auditory, visual or cognitive impairments as well as individuals with psychotic symptoms, acute crisis or at risk of self-harm appear not to be eligible for tele-psychiatry. ${ }^{52}$ The inability of patients to receive the psychological and relational support, which previously all professionals of MHC regularly provided them, could represent one of the reasons for the increased UPC in ER, as observed by other authors. ${ }^{47}$

Our results show that the sample of patients was homogeneous over the two years with regard to the demographic and social characteristics, except for nationality and work activity. In 2020, there was an increase of UPCs required by foreign patients, both European and nonEuropean, and a parallel reduction of Italians. These changes do not appear to be of univocal interpretation. However, the increase in the percentage of UPCs due to socio-environmental emergencies could plausibly be explained by the weaker social network of foreign individuals, as observed by another recent study, which has highlighted that precarious environmental conditions represent a cause of psychological distress in immigrants. ${ }^{53}$ Regarding the work status of individuals who required UPCs, there was an increase of both employed and retired patients, probably due to the 
concerns for the ongoing economic crisis which have led them to require psychological support. On the contrary, we reported a reduction in the number of students who needed UPC. We suppose that also this result can be more or less directly correlated with the COVID-19 pandemic since we hypothesize that most offsite students, who represent the majority of the student population in Modena, ${ }^{54}$ probably returned to their cities of origin due to the social isolation imposed by safety measures. We reported a statistically significant difference not in the ICD-9-CM diagnoses of the patients who required UPC in the two observation periods but in the clinical reasons for UPCs: in 2020, aggressiveness, psycho-organic disorders and maladjustment disorders with anxiety and depressed mood increased in comparison with the previous year. We hypothesize that pandemic situation could be the cause of the increase in aggressive behaviour, as historically highlighted in catastrophes $^{55}$ and maladjustment disorders with depressed mood as reported by a recent study, ${ }^{43}$ both conditions potentially related to the social environmental distress triggered by COVID-19 pandemic. In particular, as mentioned above, the absence of a protective and supportive social network may have led the most vulnerable people to go to the emergency room for help. ${ }^{44}$ In line with other studies all over the world, ${ }^{4,56,57}$ we reported a reduction in the percentage of suicidal behaviour, probably because, in this initial phase of pandemic emergency, a selfpreservation instinct prevailed over the external and collective danger of mortal infection, in accordance with the historical findings of Morselli and Durkheim, who reported a decreased rate of suicidal behaviour during wars or profound social crises. ${ }^{58,59}$ On the other hand, this result, could represent the patients' difficulties in requesting help during pandemic, especially if they suffered from feelings of helplessness which fostered suicidal behaviour. ${ }^{57}$ Nevertheless, other authors found an increase in suicide attempt ${ }^{44}$ and intense suicidal ideation ${ }^{24}$ among patients affected by psychiatric disorders during pandemic, whereas other studies reported unchanged rates. ${ }^{48,60}$ However, in the near future when the emergency situation is over, the distress experiences of pandemic could lead to an increase in self-injurious behaviour as another study evidenced. $^{61}$ This prediction is based on research conducted on past epidemics, which showed an increase of Post-Traumatic Stress Disorder, major depression and selfinjurious behaviour only several months after the end of the moment of emergency. ${ }^{13,61,62}$ Another variation was observed in the number of UPCs for psycho-organic disorders decreased in 2020, probably motivated by the global reduction of psychiatric clinical activities due to the pandemic measures. Differently from the previous year, in 2020, we reported a decreased percentage of patients who required UPCs for acute psychosis, depressive and anxiety disorders, which may be attributable to many stress triggers related to pandemic (forced lockdown, fear of infection, reduced treatment adherence, social isolation, etc.) that led to the general reduction in ER of all consultations not related to COVID-19, as reported by other authors during the pandemic. ${ }^{40,45}$ Patients with mood disorders probably avoided UPC in ER due to their fear of contamination $^{63}$ or, otherwise, they found sufficient care and stabilization in tele-psychiatry. ${ }^{64}$ This last result is partially in line with other studies, which observed a higher number of consultations for patients suffering from anxiety and depressive disorders. ${ }^{22,45}$ Our results suggest that manic status was a protective factor for UPC in pandemic, confirming the observation of another study which highlighted that a potentially severe disorder such as manic state could be a defensive and protective condition from acute post-traumatic stress symptoms induced by pandemic. $^{65}$

The analysis of UPC outcomes was statistically significantly different between the two observation periods: in 2020, psychiatric hospitalizations decreased and, concurrently, the discharge at home and the referral to outpatient services, in particular to the local MHC, increased. Consistent with these data, the therapeutic prescriptions in UPCs increased, whereas the other therapeutic measures carried out in the emergency room were not significantly modified. These results globally indicate that, in accordance with the Ministerial directives, hospitalizations to psychiatric units were limited to extreme severe and acute clinical situations to avoid the spread of COVID-19 infection as much as possible. ${ }^{10,34}$

Regarding the clinical characteristics of patients who required UPC in 2020, we observed a reduction in medical comorbidities as well as in dual diagnosis with use of alcohol/substances, suggesting that the majority of patients who required UPC in ER during pandemic suffered from a psychiatric disorder without any substance and/or medical comorbidity. This result is not in line with other studies which observed an increase of substance and, in particular, alcohol use during pandemic. ${ }^{66}$ An explanation could be represented by the use of alternative settings, such as outpatient drug abuse service or general practitioner, for the management of minor emergencies in 
patients with substance and/or alcohol use, excluding states of alcohol and drug intoxication whose frequency remained almost stable in the two years. Regarding the reduced rate of substance use, we can hypothesize that the pandemic restrictions and social isolation could have reduced the diffusion of illegal substances and consequently their abuse, especially during the restricted lockdown. This hypothesis is in line with the findings of another Italian study, which highlighted an overall significant reduction in the use of substances during the lockdown period compared with the pre-lockdown control period and significant changes in drug/alcohol use patterns during Covid-19 confinement. ${ }^{67}$ Our observations were confirmed by the regression model applied, which highlighted as risk factors for UPC in ER living in a psychiatric facility, being a patient in care in MHC, suffering from maladjustment disorders and not being affected by any medical disorders. On the contrary, being student, use of substance and alcohol in comorbidity, suffering from manic state, other motivations for UPC (as anorexia and other eating disturbances) and having been diagnosed with psychiatric diagnoses were protective factors for seeking help in ER during pandemic.

All our results suggest that, during pandemic, social environmental factors more than clinical variables conditioned the request of UPCs in ER. In particular, people already in care in MHC and/or living in psychiatric facilities showed extreme vulnerability to the impact of pandemic emergency. Further changes in the population's request for psychological support can be expected, in line with the evolution of pandemic events. We hypothesize in accordance with other catastrophic events that, once the emergency has been overcome, we could observe an increase in anxiety and depression as well as posttraumatic stress disorders and self-harm behaviour. ${ }^{61,62}$

In light of our results, we agree with the authors who alert us to the risk of a mental health pandemic following the COVID-19 epidemic, ${ }^{42,49,68}$ especially for the most fragile, socially vulnerable people who closely depend on services' support and need stable living environment conditions. This ongoing pandemic could represent a challenge that can paradoxically improve the treatment and care of people with psychiatric disorders as many authors hope. ${ }^{42,49,68,69}$ More psychological interventions for supporting vulnerable groups, more psychiatric assessment and treatments for long-term consequences of COVID-19 and more preventive activities for the population should be implemented to counteract the impact of the "virus that silently stalks" over the world.

\section{Limitations and Advantages of the Study}

Although the sample of patients is large, the analysis is restricted to the catchment area of the province of Modena. This limits the generalizability of the results to the Italian population. Furthermore, the design of the retrospective study does not allow us to infer causation. Another major limitation can be represented by the 2020 pandemic comparison only to 2019 and not to additional previous years in order to identify UPC trends in more detail.

It was difficult to find some variables, especially social and demographic ones, which were collected in the database of MHC and/or ER for clinical and epidemiological purposes. Another limitation can be represented by the use of ICD-9-CM instead of the more recent disorder classification systems (DSM-5 or ICD-10), due to our local guideline indications. On the other hand, this study, which was promptly conducted during the pandemic emergency in the lockdown period from March to May 2020 and the following three months, provides a detailed and timely picture of the real world, in line with the literature.

\section{Conclusions}

The pandemic emergency has significantly reduced the total number of urgent psychiatric consultations in the emergency room, but, at the same time, has increased the demand for UPC from the most clinically and socially vulnerable individuals, more exposed to the changes occurring in healthcare setting of outpatient services as well as to the economic and social difficulties imposed by the COVID-19 epidemic. In fact, we observed that people already being treated by psychiatric services, people living in psychiatric structures and non-Italians, therefore potentially more fragile and vulnerable, more frequently requested UPCs in 2020 than in the previous year. At the same time, among motivations for UPCs, aggression and maladjustment disorders with depressed mood increased in 2020, suggesting that the socio-environmental emergency probably related to the difficulties of the COVID-19 pandemic has strongly conditioned the requests for psychiatric treatment and care. These observations can also be explained by the reduction of the normal daily clinical activities offered by outpatient 
psychiatric services which have been forced to limit their clinical activities to urgent and serious cases, also reducing hospital admissions, in accordance with the directives issued by the Ministry of Health. These results are totally in line with those of most studies all over the world, suggesting that pandemic conditions have similar impact on the population beyond the cultural and social differences of each country.

Our study may be relevant for all healthcare professionals who have to deal with psychiatric emergencies in the ER, which represents the setting where accuracy in diagnosis and prognosis can condition and shape the treatment outcome, even during the COVID-19 pandemic.

We hope to have contributed to illustrating the changes in urgent psychiatric interventions observed in emergency room during the COVID-19 pandemic, which has dramatically and rapidly changed both normal and pathological behaviour.

\section{Abbreviations}

UPC, Urgent Psychiatric Consultation; ER, Emergency Room; PTSD, Post-Traumatic Stress Disorder; WHO, World Health Organization; SARS-CoV-2, Severe Acute Respiratory Syndrome-Coronavirus-2; MERS, Respiratory Syndrome; PE, Psychiatric Emergency; IES-R, Impact of Events Scale - Revised; DASS-21, Depression, Anxiety and Stress Scale - 21; MHC, Mental Health Centre; OCSAE, Ospedale Civile S.Agostino Estense.

\section{Data Sharing Statement}

All data are included in the manuscript. However, further data to support the current findings can be provided by the corresponding author upon reasonable request.

\section{Ethics Approval and Consent to Participate}

This research was carried out in accordance with the principles of the Helsinki Declaration (World Medical Association Declaration of Helsinki, 1964) and good clinical practice. This study was approved by the Ethics Committee of the Vasta Emilia Nord Area on 03/12/2020 (protocol n. 35176) and authorized by Azienda Ospedaliero-Universitaria (AOU) of Modena on 18/12/20 (protocols: n. 36934/20 and n. 36936/20). In accordance with the indications of our Ethics Committee, patient informed consent was not required for all patients due to the retrospective design of this study.

\section{Consent for Publication}

Not applicable.

\section{Acknowledgments}

The authors thank Orianna Raggioli for her precious help in language revision.

\section{Author Contributions}

All authors made a significant contribution to the work reported, whether that is in the conception, study design, execution, acquisition of data, analysis and interpretation, or in all these areas; took part in drafting, revising or critically reviewing the article; gave final approval of the version to be published; have agreed on the journal to which the article has been submitted; and agree to be accountable for all aspects of the work.

\section{Funding}

The authors declare that this study was not supported by any funding.

\section{Disclosure}

The authors report no actual or potential conflicts of interest.

\section{References}

1. López-Ibor JJ. Disasters and mental health: new challenges for the psychiatric profession. World J Biol Psychiatry. 2006;7(3):171-182. doi:10.1080/15622970500428735

2. Schulberg HC. Disaster, crisis theory, and intervention strategies. OMEGA. 1974;5(1):77-87. doi:10.2190/CTRK-J0LC-K6JA-EJ41

3. Fergusson DM, Horwood LJ, Boden JM, Mulder RT. Impact of a major disaster on the mental health of a well-studied cohort. JAMA Psychiatry. 2014;71(9):1025-1031. doi:10.1001/ jamapsychiatry.2014.652

4. Chou FH, Wu HC, Chou P, et al. Epidemiologic psychiatric studies on post-disaster impact among Chi-Chi earthquake survivors in Yu-Chi, Taiwan. Psychiatry Clin Neurosci. 2007;61(4):370-378. doi:10.1111/ j.1440-1819.2007.01688.x

5. Hori A, Hoshino H, Miura I, et al. Psychiatric outpatients after the 3.11 complex disaster in Fukushima, Japan. Ann Glob Health. 2016;82 (5):798-805. doi:10.1016/j.aogh.2016.09.010

6. Petrazzi L, Striuli R, Polidoro L, et al. Causes of hospitalization before and after the 2009 L'Aquila earthquake. Intern Med J. 2013;43 (9):1031-1034. doi:10.1111/imj.12238

7. Huang C, Wang Y, Li X, et al. Clinical features of patients infected with 2019 novel coronavirus in Wuhan, China. Lancet. 2020;395 (10223):497-506. doi:10.1016/S0140-6736(20)30183-5

8. Chen N, Zhou M, Dong X, et al. Epidemiological and clinical characteristics of 99 cases of 2019 novel coronavirus pneumonia in Wuhan, China: a descriptive study. Lancet. 2020;395 (10223):507-513. doi:10.1016/S0140-6736(20)30211-7

9. International Committee on Taxonomy of Virus. International committee on taxonomy of virus. Available from: https://talk.ictvonline.org/. Accessed August 14, 2020. 
10. Ministry of Health. New Coronavirus. 2020. Available from: http:/ www.salute.gov.it/portale/nuovocoronavirus/ homeNuovoCoronavirus.jsp. Accessed November 20, 2020.

11. Decree of the President of the Council of Ministers. Further implementing provisions of the decree-law of 23 February 2020, n.6 containing urgent measures of containment and management of the COVID-19 epidemiological emergency applicable throughout the national territory. 2020. Available from: http://www.trovanorme. salute.gov.it/norme/dettaglioAtto?id=73629\&completo=true.

Accessed August 14, 2020.

12. Talevi D, Socci V, Carai M, et al. Mental health outcomes of the CoViD-19 pandemic. Riv Psichiatr. 2020;55(3):137-144. doi: $10.1708 / 3382.33569$

13. Chua SE, Cheung V, McAlonan GM, et al. Stress and psychological impact on SARS patients during the outbreak. Can J Psychiatry. 2004;49(6):385-390. doi:10.1177/070674370404900607

14. World Health Organization. The impact of COVID-19 on mental, neurological and substance use services: results of a rapid assessment. 2020. Available from: https:/www.who.int/publications/ i/item/978924012455. Accessed November 10, 2020.

15. Heitzman J. Impact of COVID-19 pandemic on mental health. Psychiatr Pol. 2020;54(2):187-198. doi:10.12740/PP/120373

16. Jeong H, Yim HW, Song YJ, et al. Mental health status of people isolated due to Middle East Respiratory Syndrome. Epidemiol Health. 2016;38:e2016048. doi:10.4178/epih.e2016048

17. Gu J, Zhong Y, Hao Y, et al. Preventive behaviors and mental distress in response to $\mathrm{H} 1 \mathrm{~N} 1$ among university students in Guangzhou, China. Asia Pac J Public Health. 2015;27(2):1867-1879. doi:10.1177/1010539512443699

18. Menninger KA. Psychoses associated with influenza. JAMA. 1919;72 (4):235-241. doi:10.1001/jama.1919.02610040001001

19. Kelly BD. Plagues, pandemics and epidemics in Irish history prior to COVID-19 (coronavirus): what can we learn? Ir J Psychol Med. 2020;37(4):269-274. doi:10.1017/ipm.2020.25

20. Chevance A, Gourion D, Hoertel N, et al. Ensuring mental health care during the SARS-CoV-2 epidemic in France: a narrative review. Encephale. 2020;46(3):193-201. doi:10.1016/j. encep.2020.04.005

21. Vindegaard N, Benros MECOVID-19. pandemic and mental health consequences: systematic review of the current evidence. Brain Behav Immun. 2020;89:531-542. doi:10.1016/j.bbi.2020.05.048

22. Salari N, Hosseinian-Far A, Jalali R, et al. Prevalence of stress, anxiety, depression among the general population during the COVID-19 pandemic: a systematic review and meta-analysis. Global Health. 2020;16(1):57. doi:10.1186/s12992-020-00589-w

23. Wang $\mathrm{C}$, Pan $\mathrm{R}$, Wan $\mathrm{X}$, et al. Immediate psychological responses and associated factors during the initial stage of the 2019 Coronavirus Disease (COVID-19) epidemic among the general population in China. Int $J$ Environ Res Public Health. 2020;17(5):1729. doi:10.3390/ijerph17051729

24. Hao F, Tan W, Jiang L, et al. Do psychiatric patients experience more psychiatric symptoms during COVID-19 pandemic and lockdown? A case-control study with service and research implications for immunopsychiatry. Brain Behav Immun. 2020;87:100-106. doi:10.1016/j.bbi.2020.04.069

25. Torales J, O’Higgins M, Castaldelli-Maia JM, Ventriglio A. The outbreak of COVID-19 coronavirus and its impact on global mental health. Int J Soc Psychiatry. 2020;66(4):317-320. doi:10.1177/ 0020764020915212

26. Kontoangelos K, Economou M, Papageorgiou C. Mental health effects of COVID-19 pandemia: a review of clinical and psychological traits. Psychiatry Investig. 2020;17(6):491-505. doi:10.30773/ pi.2020.0161

27. Glick RL, Zeller SL, Berlin JS. Emergency Psychiatry: Principles and Practice. 2nd ed. Philadelphia: Lippincott Williams \& Wilkins; 2020 .
28. Wheat S, Dschida D, Talen MR. Psychiatric emergencies. Prim Care. 2016;43(2):341-354. doi:10.1016/j.pop.2016.01.009

29. Ministry of Health. Italian guidelines on hospital triage. 2012. Available from: http://www.salute.gov.it/imgs/C_17_notizie_3849 listaFile_itemName_1_file.pdf. Accessed September 28, 2020.

30. Iserson $\mathrm{KV}$, Moskop JC. Triage in medicine, part I: concept, history, and types. Ann Emerg Med. 2007;49(3):275-281. doi:10.1016/j. annemergmed.2006.05.019

31. Christian MD. Triage. Crit Care Clin. 2019;35(4):575-589. doi:10.1016/j.ccc.2019.06.009

32. Zun LS. Pitfalls in the care of the psychiatric patient in the emergency department. J Emerg Med. 2012;43(5):829-835. doi:10.1016/j. jemermed.2012.01.064

33. Mavrogiorgou P, Brüne M, Juckel G. The management of psychiatric emergencies. Dtsch Arztebl Int. 2011;108(13):222-230. doi:10.3238/ arztebl.2011.0222

34. Berring LL. De-Escalation nei servizi di salute mentale della Selandia. 6th ed. Region Sjælland: SDU; 2017.

35. Decree of the President of the Council of Ministers. Further implementing provisions of the decree-law of 23 February 2020, n.6 containing urgent measures of containment and management of the COVID-19 epidemiological emergency. Official J Italian Republic. 2020. Available from. https://www.gazzettaufficiale.it/eli/id/2020/03/08/20A01522/sg.

36. Decree of the President of the Council of Ministers. Further implementing provisions of the decree-law of 23 February 2020, n.6 containing urgent measures of containment and management of the COVID-19 epidemiological emergency applicable throughout the national territory. Off $J$ Italian Republic. 2020. Available from: https://www.gazzettaufficiale.it/eli/id/2020/03/11/20A01605/sg

37. Coronavirus statistics. Coronavirus statistics in Modena. Available from: https://statistichecoronavirus.it/coronavirus-italia/coronavirusemilia-romagna/coronavirus-modena/. Accessed March 26, 2021.

38. Ministry of Labour, Health and Social Policy. International Classification of Diseases-9th Revision-Clinical Modification. Roma, Italy: Istituto Poligrafico e Zecca dello Stato; 2008.

39. Silverman MM, Berman AL, Sanddal ND, O'carroll PW, Joiner TE. Rebuilding the tower of Babel: a revised nomenclature for the study of suicide and suicidal behaviors. Part 2: suicide-related ideations, communications, and behaviors. Suicide Life Threat Behav. 2007;37 (3):264-277. doi:10.1521/suli.2007.37.3.264

40. Department of Mental Health and Pathological Dependences. Available from: http://www.ausl.mo.it/salute-mentale. Accessed April 1, 2021.

41. Giamello JD, Abram S, Bernardi S, Lauria G. The emergency department in the COVID-19 era. Who are we missing? Eur J Emerg Med. 2020;27(4):305-306. doi:10.1097/MEJ.0000000000000718

42. Brooks SK, Webster RK, Smith LE, et al. The psychological impact of quarantine and how to reduce it: rapid review of the evidence. Lancet. 2020;395(10227):912-920. doi:10.1016/S0140-6736(20)30460-8

43. Gonçalves-Pinho M, Mota P, Ribeiro J, Macedo S, Freitas A. The impact of COVID-19 pandemic on psychiatric emergency department visits - a descriptive study. Psychiatr Q. 2020;1-11. doi:10.1007/ s11126-020-09837-z

44. Capuzzi E, Di Brita C, Caldiroli A, et al. Psychiatric emergency care during Coronavirus 2019 (COVID 19) pandemic lockdown: results from a Department of Mental Health and Addiction of northern Italy. Psychiatry Res. 2020;293:113463. doi:10.1016/j.psychres.2020.113463

45. Dragovic M, Pascu V, Hall T, Ingram J, Waters F. Emergency department mental health presentations before and during the COVID-19 outbreak in Western Australia. Australas Psychiatry. 2020;28 (6):627-631. doi:10.1177/1039856220960673

46. Di Lorenzo R, Fiore G, Bruno A, et al. Urgent psychiatric consultations at mental health center during COVID-19 pandemic: retrospective observational study. Psychiatr Q. 2021;26:1-19. doi:10.1007/ s11126-021-09907-w 
47. Carpiniello B, Tusconi M, Di Sciascio G, Zanalda E, Di Giannantonio M. Executive Committee of the Italian Society of Psychiatry. Mental health services in Italy during the COVID-19 pandemic. Psychiatry Clin Neurosci. 2020;74(8):442-443. doi:10.1111/pcn.13082

48. Seifert J, Meissner C, Birkenstock A, et al. Peripandemic psychiatric emergencies: impact of the COVID-19 pandemic on patients according to diagnostic subgroup. Eur Arch Psychiatry Clin Neurosci. 2021;271(2):259-270. doi:10.1007/s00406-020-01228-6

49. Moreno C, Wykes T, Galderisi S, et al. How mental health care should change as a consequence of the COVID-19 pandemic. Lancet Psychiatry. 2020;7:813-824. doi:10.1016/S2215-0366(20) 30307-2

50. Di Carlo F, Sociali A, Picutti E, et al. Telepsychiatry and other cutting-edge technologies in COVID-19 pandemic: bridging the distance in mental health assistance. Int J Clin Pract. 2021;75(1): e13716. doi:10.1111/ijcp.13716

51. Chen JA, Chung WJ, Young SK, et al. COVID-19 and telepsychiatry: early outpatient experiences and implications for the future. Gen Hosp Psychiatry. 2020;66:89-95. doi:10.1016/j. genhosppsych.2020.07.002

52. Cowan KE, McKean AJ, Gentry MT, Hilty DM. Barriers to use of telepsychiatry: clinicians as Gatekeepers. Mayo Clin Proc. 2019;94 (12):2510-2523. doi:10.1016/j.mayocp.2019.04.018

53. Ilić B, Švab V, Sedić B, Kovačević I, Friganović A, Jurić E. Mental health in domesticated immigrant population - a systematic review. Psychiatr Danub. 2017;29(3):273-281. doi:10.24869/psyd.2017.273

54. National Institute of Statistics. University indicators. Available from: http://dati.istat.it/Index.aspx?DataSetCode=DCIS_ISCRITTI_COM A. Accessed November 25, 2020.

55. Zeeman EC. Catastrophe Theory. Sci Am. 1976;234(4):65-83.

56. Ferrando SJ, Klepacz L, Lynch S, et al. Psychiatric emergencies during the height of the COVID-19 pandemic in the suburban New York City area. J Psychiatr Res. 2020;136:552-559. doi:10.1016/j.jpsychires.2020.10.029

57. Hernández-Calle D, Martínez-Alés G, Mediavilla R, et al. Trends in psychiatric emergency department visits due to suicidal ideation and suicide attempts during the COVID-19 pandemic in Madrid, Spain. J Clin Psychiatry. 2020;81(5):20113419. doi:10.4088/JCP.20113419

58. Morselli E. Suicide: An Essay on Comparative Moral Statistics. London, UK: Kegan Paul \& Co.; 1881.

59. Durkheim E. Suicide. New York, NY: The Free Press; 1966.
60. McAndrew J, O’Leary J, Cotter D, et al. Impact of initial COVID-19 restrictions on psychiatry presentations to the emergency department of a large academic teaching hospital. Ir J Psychlog Med. 2020:1-8. doi:10.1017/ipm.2020.115.

61. Huremović D. Psychiatry of Pandemics - a Mental Health Response to Infection Outbreak. Manhasset, NY: Springer; 2019.

62. Taylor S. The Psychology of Pandemics: Preparing for the Next Global Outbreak of Infectious Disease. Newcastle upon Tyne: Cambridge Scholars Publishing; 2019.

63. Forte G, Favieri F, Tambelli R, Casagrande M. The enemy which sealed the world: effects of covid-19 diffusion on the psychological state of the Italian population. J Clin Med. 2020;9(6):1802. doi:10.3390/jcm9061802.390/jcm9061802

64. Yellowlees P, Nakagawa K, Pakyurek M, Hanson A, Elder J, Kales HC. Rapid Conversion of an Outpatient Psychiatric Clinic to a 100\% Virtual Telepsychiatry Clinic in Response to COVID-19. Psychiatr Serv. 2020;71(7):749-752. doi:10.1176/appi.ps.202000230

65. Carmassi C, Bertelloni CA, Dell'Oste V, et al. Tele-psychiatry assessment of post-traumatic stress symptoms in 100 patients with bipolar disorder during the COVID-19 pandemic social-distancing measures in Italy. Front Psychiatry. 2020;11:580736. doi:10.3389/ fpsyt.2020.580736

66. Pollard MS, Tucker JS, Green HD Jr. Changes in adult alcohol use and consequences during the COVID-19 pandemic in the US. JAMA Network Open. 2020;3(9):e2022942. doi:10.1001/ jamanetworkopen.2020.22942

67. Gili A, Bacci M, Aroni K, et al. Changes in drug use patterns during the COVID-19 pandemic in Italy: monitoring a vulnerable group by hair analysis. Int J Environ Res Public Health. 2021;18(4):1967. doi:10.3390/ijerph18041967

68. Fiorillo A, Gorwood P. The consequences of the COVID-19 pandemic on mental health and implications for clinical practice. Eur Psychiatry. 2020;63(1):e32. doi:10.1192/j.eurpsy.2020.35

69. Bojdani E, Rajagopalan A, Chen A, et al. COVID-19 Pandemic: impact on psychiatric care in the United States. Psychiatry Res. 2020;289:113069. doi:10.1016/j.psychres.2020.113069

70. Joseph Robinette Biden Jr. Inaugural Address by President Joseph R. Biden, Jr. Available from: https://www.nytimes.com/2021/01/20/ us/politics/biden-inauguration-speech-transcript.html. Accessed January. 31, 2021.
Neuropsychiatric Disease and Treatment

\section{Publish your work in this journal}

Neuropsychiatric Disease and Treatment is an international, peerreviewed journal of clinical therapeutics and pharmacology focusing on concise rapid reporting of clinical or pre-clinical studies on a range of neuropsychiatric and neurological disorders. This journal is indexed on PubMed Central, the 'PsycINFO' database and CAS, and is the official journal of The International Neuropsychiatric Association (INA). The manuscript management system is completely online and includes a very quick and fair peer-review system, which is all easy to use. Visit http://www.dovepress.com/testimonials.php to read real quotes from published authors. 